\title{
Genital Dysplasia in Women Infected with Human Immunodeficiency Virus
}

\author{
Gregory Taylor, MD, Tracy Wolff, MD, Niharika Khanna, MD, Priscilla Furth, MD, \\ and Patricia Langenberg, $P h D^{*}$
}

Background: Women infected with human immunodeficiency virus (HIV) are at increased risk for the development of dysplastic genital lesions. Traditionally, markers of immunosuppression were predictive of the development of dysplasia. Recent advances in antiretroviral medications allow restoration of a once-depressed $\mathrm{CD}_{4}^{+}$cell count and suppression of HIV replication. In this new era, additional predictive markers of genital dysplasia are needed for management of women infected with with HIV.

Objective: To find predictive markers of genital dysplasia in women infected with HIV.

Design: Observational study of a consecutive sample of 200 women infected with HIV from an urban university clinic. Measurements of histopathology, $\mathrm{CD}^{+}$count, $\mathrm{CD} 4^{+}$nadir, HIV viral load, human papillomavirus (HPV), and usage of highly active antiretroviral therapy (HAART) were evaluated for an association with genital dysplasia.

Results: There was a trend toward a protective effect against any genital dysplasia when HAART had been prescribed [relative risk $=0.77,95 \%$ confidence interval $(\mathrm{CI}) 0.56,1.06$ ] and HAART therapy resulted in an immune response (relative risk, 0.61 ; 95\% CI, 36, 1.02). High-risk HPV DNA was a strong predictor of dysplasia $(P=.0003)$. A lower $\mathrm{CD}^{+}$count nadir was strongly associated with genital dysplasia $(P=.0003)$.

Conclusion: A history of greater immunosuppression, as measured by the nadir of a patient's $\mathrm{CD}^{+}$ count, is the strongest predictor of genital dysplasia in women infected with HIV. (J Am Board Fam Pract 2004;17:108-13.)

There is an increase in the rates of both detection and persistence of human papillomavirus (HPV) infection in women coinfected with human immunodeficiency virus (HIV). Up to $20 \%$ of these coinfected patients develop HPV-induced premalignant lesions of the uterine cervix within 3 years of HIV diagnosis. ${ }^{1-6}$ The progression of an untreated $\mathrm{HPV}$-induced dysplastic lesion may lead to invasive cervical cancer, an AIDS-defining illness. ${ }^{6,7}$

Before highly active antiretroviral therapy (HAART) became the standard of care in the treatment of persons infected with HIV, the risk of

Submitted, revised, 10 September 2003.

From the Department of Family Medicine (GT, TW, NK), Institute of Human Virology (GT, PF), Department of Epidemiology (PL), and the Greenebaum Cancer Center (GT, NK, PF, PL), University of Maryland, Baltimore. Address correspondence to Gregory Taylor, MD, University of Maryland, 29 S. Greene St., Suite 300, Baltimore, MD 21201.

*Present address: Lombardi Cancer Center, Georgetown University, Washington, DC.

This work was partially supported by grants from the American Academy of Family Practice Foundation, United States Public Health Service training grant HL07612-14, the National Cancer Institute, and Digene. cervical dysplasia increased progressively as a patient's immune function declined, as measured by the decrement of $\mathrm{CD}^{+}{ }^{\text {cells. }}{ }^{2,8-11}$ It has also been observed that women with low $\mathrm{CD}^{+}{ }^{+}$counts experience greater rates of cervical lesion recurrence and progression when treated by the traditional ablative methods of loop electrosurgical excision procedure or cone biopsy. ${ }^{9,12,13}$ With the advent of newer antiretroviral medications and HAART therapy, it became possible to reverse the depletion of CD4 cells in a person infected with HIV. Opposing studies with small numbers of HIV-positive patients have revealed minimal to no effect of antiretroviral agents on the incidence of cervical dysplasia $^{14-17}$ Two of the studies that failed to reveal a positive effect were performed before HAART became the standard of care. ${ }^{6,18}$ Current guidelines suggest yearly Papanicolaou smears for HIV-positive women with a history of a normal Papanicolaou smear in the past, and every 6 months if the patient's CD4 count is below 200. These guidelines do not acknowledge the influence of HAART on immune perimeters and cervical dysplasia. ${ }^{19}$ It is unclear whether immune restoration brought about 
by HAART will be protective against genital dysplasia or influence the natural course and treatment of HPV-related genital dysplasia. Markers that may be predictive of genital dysplasia in HIV-positive patients need to be extrapolated from those who have been treated with antiretroviral agents. To investigate whether HAART has an affect on cervical dysplasia, we collected data on a consecutive sample of women infected with HIV undergoing colposcopic examination, starting in 1997, after the widespread institution of HAART.

\section{Methods}

Two hundred HIV-positive women underwent standard colposcopic examination between October 1997 and December 2001 at an urban university hospital infectious disease clinic that is used to train Family Medicine residents in colposcopy. Women had been referred for colposcopic examination because of a recent abnormal Papanicolaou smear, self-reported abnormalities on Papanicolaou smear, current external HPV infection, or a history of genital dysplasia. At the time of colposcopy, all women were offered supplemental screening for HPV DNA by the Digene Hybrid Capture II method; 160 women accepted. Of these samples, 79 of the high-risk HPV were available for calculation of the relative light unit, a semiquantitative measure of the amount of HPV DNA. Cervical, endocervical, vaginal, and/or vulvar biopsies were performed as indicated by direct visualization during colposcopic examination. Additional data included $\mathrm{CD}^{+}{ }^{+}$count, HIV viral loads collected within the 3 months preceding colposcopy, $\mathrm{CD}^{+}$nadir, and changes in $\mathrm{CD}^{+}{ }^{+}$and viral load. The administration of HAART, as defined by the US Department of Health and Human Services guidelines to include at least 3 antiretroviral medications, was recorded. ${ }^{20}$ All antiretroviral medications had been prescribed by the patient's current health care provider. Data on age, parity, risk factor for HIV infection, and race were collected. Patients who had an undetectable viral load or a $1.5 \log$ or greater drop in viral load or a greater than 100 count increase in $\mathrm{CD}^{+}$for at least 3 months after initiation of HAART were defined as demonstrating an immune response to HAART.

Outcome variables were histology of biopsy results, categorized as no dysplasia, mild dysplasia (mild, VAIN I, VIN I), and severe dysplasia (mod-
Table 1. Description of the Sample of HIV-Positive Women Presenting for Colposcopy

\begin{tabular}{lrc}
\hline Variable & Number & Percent \\
\hline All Women & 200 & 100 \\
African American & 183 & 91.5 \\
White & 16 & 8.0 \\
Other & 1 & 0.7 \\
Route of Infection & & \\
IV Drug & 95 & 47.5 \\
Heterosexual & 46 & 23.0 \\
Transfusion & 2 & 1.0 \\
Unknown & 57 & 28.5 \\
Histopathology & & \\
Normal or other & 125 & 62.5 \\
Mild dysplasia & 31 & 15.5 \\
Moderate dysplasia & 26 & 13 \\
Severe dysplasia & 11 & 18.2 \\
Cancer & 1 & 0.5 \\
Can not grade & 1 & 0.5 \\
Mild vaginal dysplasia & 1 & 0.5 \\
Severe vaginal dysplasia & 2 & 1 \\
Vaginal cancer & 2 & 1 \\
\hline & & \\
\hline & & \\
\hline
\end{tabular}

erate, severe, CIS, VAIN II-III, VIN II-III). Predictor variables included HAART therapy; immune response to HAART therapy; $\mathrm{CD}^{+}{ }^{+}$count, either as a continuous variable or categorized as $<200 /$ $\mu \mathrm{L}, \geq 200 \mu \mathrm{L}$; $\mathrm{CD}^{+}{ }^{+}$count nadir; HIV viral load, either as continuous log-transformed or categorized as $<10,000$ copies $/ \mathrm{mL}, \geq 10,000$ copies $/ \mathrm{mL}$ peak viral load, log-transformed; whether viral load was ever nondetectable; and positive high-risk $\mathrm{HPV}$. Other covariates evaluated were age, race, and reported route of HIV acquisition. Bivariate statistical analyses used $\chi^{2}$ tests to compare categorical variables on proportions with none, mild, or severe dysplasia. For continuous variables, one-way analyses of variance were used to compare means of those with none, mild, and severe dysplasia. Multiple logistic regression models were developed to assess the effects of HAART therapy and other predictor variables on dysplasia, adjusted for confounding variables. Adjusted odds ratios (OR) with 95\% confidence intervals (CI) were computed. Variables were included in models if they were associated with dysplasia at $P<.10$ or if inclusion changed the OR for HAART therapy substantially. All analyses were conducted using SAS (version 8.2; SAS Institute, Cary, NC).

\section{Results}

Table 1 presents a description of the sample of the $\mathrm{HIV}$-positive women and genital histopathology results. From the subgroup of cases in which HPV 


\begin{tabular}{|c|c|c|c|c|c|c|}
\hline Variable & $\mathrm{N}$ & Percent & $\begin{array}{l}\text { No Dysplasia } \\
(\mathrm{N}=116) \\
\mathrm{N}(\%)\end{array}$ & $\begin{array}{l}\text { Mild Dysplasia } \\
(\mathrm{N}=41) \\
\mathrm{N}(\%)\end{array}$ & $\begin{array}{c}\text { Severe } \\
\text { Dysplasia } \\
(\mathrm{N}=43) \\
\mathrm{N}(\%)\end{array}$ & $P$ Value $^{*}$ \\
\hline CD4 count $\geq 200 \mu \mathrm{L}$ & 128 & 64.3 & $85(73.3)$ & $21(51.2)$ & $22(52.4)$ & .008 \\
\hline HIV viral load $\geq 10,000$ copies $/ \mathrm{mL}$ & 85 & 43.2 & $45(38.8)$ & $22(55.0)$ & $18(43.9)$ & .20 \\
\hline Ever nondetectable & 87 & 46.8 & $56(52.8)$ & $15(38.5)$ & $16(39.0)$ & .16 \\
\hline HAART therapy $>3$ months. & 121 & 61.1 & $75(65.8)$ & $19(46.3)$ & $27(62.8)$ & .09 \\
\hline Immune response to HAART* & 96 & 48.0 & $59(50.9)$ & $15(36.6)$ & $22(51.2)$ & .26 \\
\hline \multirow[t]{2}{*}{ HPV high risk positive $(\mathrm{N}=160)$} & 125 & 78.1 & $60(66.7)$ & $31(88.6)$ & $34(97.1)$ & .0003 \\
\hline & & $\begin{array}{c}\text { Mean } \pm \text { SD } \\
\text { (Range) }\end{array}$ & Mean \pm SD & & & \\
\hline Age & 200 & $\begin{array}{c}36.4 \pm 7.3 \text { years } \\
(16 \text { to } 70)\end{array}$ & $37.4 \pm 7.5$ & $35.0 \pm 6.9$ & $35.0 \pm 6.9$ & .07 \\
\hline CD4 count & 199 & $\begin{array}{l}289 \pm 223 \mu \mathrm{L} \\
\quad(0 \text { to } 1283)\end{array}$ & $341 \pm 237$ & $213 \pm 198$ & $221 \pm 164$ & .0005 \\
\hline CD4 Nadir & 196 & $\begin{array}{l}187 \pm 176 \mu \mathrm{L} \\
\quad(0 \text { to } 1007)\end{array}$ & $228 \pm 185$ & $139 \pm 155$ & $125 \pm 139$ & .0006 \\
\hline HIV viral load $(\log 10)$ & 197 & $\begin{array}{l}3.79 \pm 1.09 \\
\quad(1.8 \text { to } 5.9)\end{array}$ & $3.64 \pm 1.03$ & $4.04 \pm 1.23$ & $3.96 \pm 1.07$ & .07 \\
\hline Peak viral load $(\log 10)$ & 192 & $\begin{array}{l}4.61 \pm 0.93 \\
\quad(2.6 \text { to } 5.9)\end{array}$ & $4.51 \pm 0.98$ & $4.85 \pm 0.82$ & $4.67 \pm 0.85$ & .12 \\
\hline
\end{tabular}

$\chi^{2}$ comparing 3 groups for percentages; one-way analysis of variance comparing means, 3 groups.

* Defined as $>100-\mu \mathrm{L}$ increase CD4 and/or $>1.5 \log$ drop in HIV viral load.

DNA was obtained, high-risk DNA was noted to be associated with higher-grade dysplasia, in that it was detected in 34 of 35 (97\%) cases of the severe dysplasia and 31 of $35(86 \%)$ cases of the mild dysplasia compared with being detected in only 60 of $90(67 \%)$ of those cases with no dysplasia $(P=$ $.0003)$. There was also a positive association of a quantitative increase in the amounts of detected high-risk HPV DNA, as measured by the relative light unit, with increasing degrees of dysplasia $(P=$ .006). No associations of race, age, or route of HIV infection with the histopathological diagnosis of mild dysplasia or severe dysplasia were found. There was a significant protective effect of a CD4 count greater than $200 \mu \mathrm{L}$ between the categories of no dysplasia (85 of 116), mild dysplasia (21 of $41)$, and severe dysplasia (22 of 42) $(P=.008)$, but a nonsignificant difference between the same groups with respect to HIV viral load greater than 10,000 copies/mL $(P=.12)$ (Table 2$)$.

Forty-four percent (89 of 200) of the patients were deemed respondent to HAART by our criteria. Respondent patients demonstrated both significantly higher mean value of their CD4 count (368.4 vs $225.62 \mu \mathrm{L}, P<.001)$ and lower mean $\log 10$ of their HIV viral loads ( $\log 3.18$ vs $4.29, P<$
.001). Patients in this category also had a borderline positive protective association with mild [relative risk $(\mathrm{RR})=0.61 ; 95 \% \mathrm{CI}=0.36,1.02)$ and severe $(\mathrm{RR}=0.50 ; 95 \% \mathrm{CI}=0.24,1.05)$ dysplasia. If a patient had ever demonstrated a nondetectable HIV viral load while on HAART, this was found to be protective for both mild dysplasia $(\mathrm{RR}=0.55$; $95 \% \mathrm{CI}=0.32,0.94)$ and severe dysplasia $(\mathrm{RR}=$ $0.32 ; 95 \% \mathrm{CI}=0.14,0.75)$. The strongest predictor of genital dysplasia was the nadir of the CD4 count mean: $137 \mu \mathrm{L}( \pm 154)$ in those with mild dysplasia, $128( \pm 142)$ in those with severe dysplasia versus $228 \mu \mathrm{L}( \pm 185)$ in those without any histologic proof of dysplasia or normal examinations $(P=.0006)$.

Several models were evaluated to determine the most parsimonious model. When included in a model with HAART therapy, neither age, race, route of infection, current HIV viral load, nor current $\mathrm{CD}^{+}$count was found to be associated with dysplasia. High-risk HPV, which was nearly perfectly associated with dysplasia, was not included in the models. Both the nadir of $\mathrm{CD}^{+}$count and nondetectability of HIV at any previous time were highly associated with HAART therapy itself. HAART therapy in turn was more strongly protec- 
tive against dysplasia when nadir of the $\mathrm{CD} 4^{+}$ count and nondetectability of the HIV virus were included in the models. $(\mathrm{OR}=0.34 ; 95 \% \mathrm{CI}, 0.17$, $0.72)$.

\section{Discussion}

Before HAART, the natural course of HIV infection led to a progressive decline in a patient's innate immunity. With the decrease of the patients' $\mathrm{CD}^{+}$count, a reciprocal increased susceptibility to various opportunistic infections occurred. Previous studies have reported a similar increase in the incidence of HPV-induced dysplasia with declining $\mathrm{CD}^{+}$counts in patients that are not treated with antiretrovirals. ${ }^{8,10}$ With the introduction of HAART in the United States, the incidence of most AIDS-defining illnesses decreased as patients experienced a numerical restoration of their $\mathrm{CD}^{+}$ lymphocyte count. ${ }^{21}$ A perplexing exception to this trend was shown in a study in which the incidence of invasive cervical cancer actually increased in the HAART era. ${ }^{22}$ Thus, those markers of the immune system that represent a successful immunorestoration against opportunistic diseases in patients infected with HIV are not yet fully defined.

In this cohort of women infected with HIV, we identified both a total $\mathrm{CD}^{+}$count below 200 and a low CD4 count nadir as immune-based markers for the risk of genital dysplasia.

Recent data showing that prolonged periods of $\mathrm{CD}^{+}{ }^{+}$lymphopenia in patients infected with HIV resulted in defects in $\mathrm{T}$ cell proliferation regardless of the current $\mathrm{CD}^{+}{ }^{+}$count or HIV viral load could explain the fact that the $\mathrm{CD}^{+}{ }^{+}$nadir was a strong predictor of dysplasia. ${ }^{23}$ This phenomenon could also result in periods of HPV proliferation and/or activation. It is possible that there is an incomplete immune restoration with HAART, and the ability to recognize and respond to HPV specific antigens is lost at lower $\mathrm{CD}+$ nadirs, which results in persistent HPV infection. This is consistent with our study, in which the $\mathrm{CD}^{+}{ }^{+}$nadir of those without high risk HPV DNA was much higher than in those with detectable HPV DNA. (238 vs 161, $P=.02)$.

We also detected a trend toward a protective effect of HAART against HPV-related genital dysplasia at the time of colposcopic examination. Of concern is that this study did not detect any direct effects of HAART, CD4, or HIV virus load on
HPV quantity, and that 60 of $90(67 \%)$ of the patients without dysplasia displayed detectable high-risk HPV DNA, which may in turn forebode future dysplasia. ${ }^{24-26}$

Weaknesses in this study are that we did not account for the nadir CD4 count at the time of HAART initiation, and many patients had antiretroviral therapy started at a lower CD4 level than is currently recommended. The timing of HAART therapy was related to both a patient's status at the time of diagnosis and/or to her willingness to start antiretroviral therapy. Whether the protective response of HAART against genital dysplasia was an effect of a partial immunorestoration or from the direct suppression of HIV or HPV could not be ascertained from these data, because there were positive influences from HAART on both of these parameters, and either one could effect the expression of HPV.

There is an important limitation to observational studies such as ours that prevents the evaluation of long-term changes in immune status or on outcomes. Another limitation of this study is that we do not have exact data on the duration of HPV infection or HIV infection

Our findings may be an important incentive for women to take HAART because recent studies have shown that women have a greater reluctance to start HAART compared with their male counterparts. ${ }^{27,28}$ Because women survive longer with HIV infection, guidelines that provide for optimal care of genital dysplasia need to be maximized. The screening guidelines for women who have experienced a low nadir CD4 count may need to be modified to encourage closer monitoring. Because many women infected with HIV receive gynecological care from their primary care provider, it will be important for them to know the natural course of HPV-related diseases. Of utmost importance is that many women infected with HIV are unaware of their status. Prompt identification of these patients is paramount, because if a woman's immune function can be preserved through earlier control of HIV infection, there may be a resultant overall decrease in the incidence of genital dysplasia and subsequent cancer.

We would like to acknowledge Sheila Lee for assistance in recruiting and management of the patients and Rachel Barnes for data collection and management. 


\section{References}

1. Ahdieh L, Munoz A, Vlahov D, Trimble CL, Timpson LA, Shah K. Cervical neoplasia and repeated positivity of human papillomavirus infection in human immunodeficiency virus-seropositive and -seronegative women. Am J Epidemiol 2000;151: $1148-57$.

2. Garzetti GG, Ciavattini A, Butini L, Vecchi A, Montroni M. Cervical dysplasia in HIV-seropositive women: role of human papillomavirus infection and immune status. Gynecol Obstet Invest 1995;40: 52-6.

3. Moscicki AB, Ellenberg JH, Vermund SH, et al. Prevalence of and risks for cervical human papillomavirus infection and squamous intraepithelial lesions in adolescent girls: impact of infection with human immunodeficiency virus. Arch Pediatr Adolesc Med 2000;154:127-34.

4. Shah K, Solomom L, Daniel R, Cohn S, Lahov D. Comparison of PCR and hybrid capture methods for detection of human papillomavirus in injection drugusing women at high risk of human immunodeficiency virus infection. J Clin Microbiol 1997:517-9.

5. Six C, Heard I, Bergeron C, et al. Comparative prevalence, incidence and short-term prognosis of cervical squamous intraepithelial lesions amongst HIV-positive and HIV-negative women. AIDS 1998;12:1047-56.

6. Ellerbrock T, Chiasson M, Bush BA, Sun X, Wright $\mathrm{T}$, et al. Incidence of cervical squamous intraepithelial lesions in HIV-infected women. JAMA 200;283: 1031-7.

7. Maiman M, Fruchter RG, Clark M, Arrastia CD, Matthews R, Gates EJ. Cervical cancer as an AIDSdefining illness. Obstet Gynecol 1997;89:76-80.

8. Petry KU, Scheffel D, Bode U, et al. Cellular immunodeficiency enhances the progression of human papillomavirus-associated cervical lesions. Int J Cancer 1994;57:836-40.

9. Ahr A, Scharl A, Lutke K, Staszewski S, Kacer PZ, Kaufmann M. Cervical intraepithelial neoplasia in human immunodeficiency virus-positive patients. Cancer Detect Prev 2000;24:179-85.

10. Schafer A, Friedmann W, Mielke M, Schwartlander B, Koch MA. The increased frequency of cervical dysplasia-neoplasia in women infected with the human immunodeficiency virus is related to the degree of immunosuppression. Am J Obstet Gynecol 1991; 164:593-9.

11. Heard I, Tassie JM, Schmitz V, Mandelbrot L, Kazatchkine MD, Orth G. Increased risk of cervical disease among human immunodeficiency virusinfected women with severe immunosuppression and high human papillomavirus load. Obstet Gynecol 2000;96:403-9.

12. Fruchter RG, Maiman M, Sedlis A, Bartley L, Camilien L, Arrastia CD. Multiple recurrences of cervical intraepithelial neoplasia in women with the human immunodeficiency virus. Obstet Gynecol 1996;87: $338-44$.

13. Maiman M. Management of cervical neoplasia in human immunodeficiency virus-infected women. J Natl Cancer Inst Monogr 1998;(23):43-9.

14. Heard I, Schmitz V, Costagliola D, Orth G, Kazatchkine MD. Early regression of cervical lesions in HIV-seropositive women receiving highly active antiretroviral therapy. AIDS 1998;12:1459-64.

15. Fiore T, Chapman S, Perry K, Stenzel M, Gormley $\mathrm{J}, \mathrm{Cu}-\mathrm{Uvin} \mathrm{S}$. Prevalence of cervical dysplasia in a cross-sectional study of HIV positive women (abstract). Program and Abstracts of the 13th International AIDS Conference; 2000 July 9-14; Durban, South Africa. Abstract MoPeB2241.

16. Lillo FB, Ferrari D, Veglia F, et al. Human papillomavirus infection and associated cervical disease in human immunodeficiency virus-infected women: effect of highly active antiretroviral therapy. J Infect Dis 2001;184:547-51.

17. Orlando G, Fasolo MM, Schiavini M, Signori R, Cargnel A. Role of highly active antiretroviral therapy in human papillomavirus-induced genital dysplasia in HIV-1-infected patients. AIDS 1999;13: 424-5.

18. Duerr A, Shah K, Klien R, Cu-Uvin S. The effect of highly active antiretroviral therapy (HAART) on cervical dysplasia and HPV infection among HIVinfected women. Program and abstracts of the 12th World AIDS Conference; 1998 June 29-July 3; Geneva, Switzerland. Abstract 60289.

19. A guide to the clinical care with women with HIV/ AIDS, 1st ed. Rockville (MD): US Department of Health and Human Services; 2001. p. 157. Available at URL: http://hab.hrsa.gov/womencare.htm

20. Guidelines for the use of antiretroviral agents in HIV-infected adults and adolescents. Rockville (MD): US Department of Health and Human Services; 2000.

21. Kaplan J, Hanson, Dworkin M, Frederick T, Jones J, et al. Epidemiology of human immunodeficiency virus-associated opportunistic infections in the United States in the era of highly active antiretroviral therapy. Clin Infect Dis 2000;30:S5-S14.

22. Dorrucci M, Suligoi B, Serraino D, et al. Incidence of invasive cervical cancer in a cohort of HIV-seropositive women before and after the introduction of highly active antiretroviral therapy. J Acquir Immune Defic Syndr 2001;26:377-80.

23. Sieg SF, Mitchem JB, Bazdar DA, Lederman MM. Close link between CD4+ and CD8 + T cell proliferation defects in patients with human immunodeficiency virus disease and relationship to extended periods of CD4+ lymphopenia. J Infect Dis 2002; 185:1401-16. 
24. Sun X, Kuhn L, Ellerbrock T, Chiasson M, Bush T, Wright T. Human papillomavirus infection in women infected with the human immunodeficiency virus. N Engl J Med 1997;337:1343-86.

25. Ho GYF, Burk RD, Klien S. Persistent genital human papillomavirus infection as a risk factor for persistent cervical dysplasia. J Natl Cancer Inst 1995; $87: 1365-71$.

26. Nagai Y, Maehama T, Asato T, Kanazawa K. Persistence of human papillomavirus infection after therapeutic conization for CIN 3: is it an alarm for disease recurrence? Gynecol Oncol 2000;79:294-9.

27. Mocroft A, Gill MJ, Davidson W, Phillips AN. Are there gender differences in starting protease inhibitors, HAART, and disease progression despite equal access to care? J Acquir Immune Defic Syndr 2000; 24:475-82.

28. Anderson K, Mitchell J. Differential access in the receipt of antiretroviral drugs for the treatment of AIDS and its implications for survival. Arch Intern Med 2000;160:3114-20. 